\title{
The CARD8 p.C10X mutation associates with a low anti-glycans antibody response in patients with Crohn's disease
}

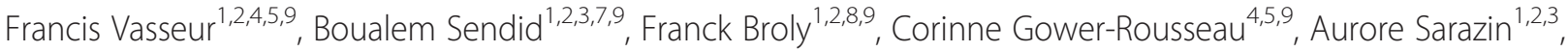 \\ Annie Standaert-Vitse ${ }^{1,2,7,9}$, Jean-Frederic Colombel ${ }^{1,2,3,6,9}$, Daniel Poulain ${ }^{1,2,3,7,9}$ and Thierry Jouault ${ }^{1,2,3,7,9^{*}}$
}

\begin{abstract}
Background: Crohn's disease (CD) is associated with elevated anti-glycans antibody response in 60\% of CD patients, and 25\% of healthy first-degree relatives (HFDRs), suggesting a genetic influence for this humoral response. In mice, anti-glucan antibody response depends on the NLRP3 inflammasome. Here, we explored the effect of mutated CARD8, a component of the inflammasome, on anti-glycans antibody response in human.

Methods: The association between p.C10X mutation (rs2043211) of the CARD8 gene and the levels of anti-glycans antibody response was examined in 39 CD families. The family-based QTDT association test was used to test for the genetic association between CARD8 p.C10X mutation and anti-glycan antibodies in the pedigrees. The difference in antibody responses determined by ELISA was tested in a subgroup of CD probands (one per family) and in a subgroup of HFDRs using the Wilcoxon Kruskal Wallis non-parametric test.

Results: The QTDT familial transmission tests showed that the p.C10X mutation of CARD8 was significantly associated with lower levels of antibody to mannans and glucans but not chitin ( $p=0.024, p=0.0028$ and $p=0.577$, for ASCA, ALCA and ACCA, respectively). These associations were independent of NOD2 and NOD1 genetic backgrounds. The p.C10X mutation significantly associated or displayed a trend toward lower ASCA and ALCA levels ( $p=0.038$ and $p=0.08$, respectively) only in the subgroup of CD probands. Such associations were not significant for ACCA levels in both subgroups of CD probands and of HFDRs.

Conclusion: Our results show that ASCA and ALCA but not ACCA levels are under the influence of CARD8 genotype. Alteration of CARD8, a component of inflammasome, is associated with lower levels of antibodies directed to mannans and glucans at least in CD patients.
\end{abstract}

Keywords: Crohn's disease, Anti-glycan antibodies, CARD8/TUCAN, ASCA/ALCA, Inflammasome, Adaptive immunity

\section{Background}

In humans, the antibody response to glycans has been associated with various infectious and autoimmune diseases [1]. Regarding yeast glycans, monitoring of the anti-mannan antibody response is used for the diagnosis of invasive C. albicans infections [2]. Other anti-mannan antibodies such as anti-S. cerevisiae antibodies (ASCA) are associated with Crohn's disease (CD) where they represent the most frequently found serological marker [3]

\footnotetext{
*Correspondence: thierry.jouault@univ-lille2.fr

'Université Lille Nord de France, 59000, Lille, France

${ }^{2}$ UDSL, 59000, Lille, France

Full list of author information is available at the end of the article
}

and at this time, the most related markers for early CD diagnosis [4]. ASCA levels are elevated in $60 \%$ of CD patients and in $25 \%$ of their healthy first-degree relatives (HFDRs) [5-7]. Although still unknown, one possible origin for this antibody response would be an abnormal adaptive response to the pathogenic yeast $C$. albicans [8]. As well as ASCA, other specific serological markers for $\mathrm{CD}$ have been described including anti-glucan (ALCA) and anti-chitin (ACCA) antibodies [9], all of them being generated during invasive C. albicans infection [10].

In this paper, we were interested in the role of caspase activating and recruitment domain 8, CARD8, also known as CARDINAL or TUCAN (tumor-up-regulated CARD-

\section{Biomed Central}

(c) 2013 Vasseur et al.; licensee BioMed Central Ltd. This is an Open Access article distributed under the terms of the Creative Commons Attribution License (http://creativecommons.org/licenses/by/2.0), which permits unrestricted use, distribution, and reproduction in any medium, provided the original work is properly cited. 
containing antagonist of caspase 9) in the regulation of anti-glycans antibodies response. CARD8 is a $48-\mathrm{kDa}$ peptide predominantly expressed in monocytes, placenta, lymph nodes, and spleen. The CARD8 gene is located at 19q13.3 between rs736289 and rs 281379 loci recently associated with $C D$ in a GWAS meta-analysis [11]. CARD8 has structural similarity with NOD1 (CARD4) and NOD2 (CARD15), whose mutations are well known risk factors for CD [12]. CARD8 protein functions as an inhibitor of apoptosis, by blocking procaspase 9, as well as an inhibitor of NF- $\mathrm{kB}$ activation [13] and it is a component of NLRP3 inflammasome [14]. NLRP3 inflammasome (formerly cryopyrin, CIAS1, and NALP3) is the best characterized inflammasome complex. It includes ASC (apoptosis-associated specklike protein), caspase 1 and CARD8 [14,15]. NLRP3 inflammasome is activated by many microbial stimuli and by endogenous danger signals such as ATP and monosodium urate [15]. Other activators include indigestible particulates like silica and alum [16] but also fungal pathogens such as C. albicans [17-20].

Assembly of inflammasome proteins enables activation of caspase 1 and, thereby, initiates the second danger signal leading to the cleavage of the inflammatory cytokine IL-1 $\beta$ into its biologically active form. IL- $1 \beta$ is involved in animal models of fungal infection, together with IL1- $\alpha$ and IL-18 [21-25]. However, there are now strong evidences that it has a significant role in modulating the adaptive immune response [26,27]. Indeed, Bcells are directly activated by $\beta$-glucans through NLRP3, suggesting a critical role of B-cell-intrinsic NLRP3 for antiglycans antibody responses [19]. NLRP3 inflammasome is thus considered to be a critical component for regulating $\beta$-glucan-induced innate $[19,28]$, but also adaptive immune responses in mice [19]. In humans, multiple NLRs are expressed in peripheral B lymphocytes, notably NOD1, NOD2, NLRP1 and NLRP3 [29]. NOD2 and NOD1 genetic variants together with their relationship with genetic susceptibility to Crohn's disease have been reported to be associated with anti-glycan antibody levels [30,31].

The deleterious mutation of CARD8 (p.C10X) predicting a stop codon at position 10, prematurely terminates the protein. This mutation has consequences for the protein's function in both inflammasome-mediated processes and NF- $\mathrm{kB}$ suppression. Several studies have thus concerned the influence of the p.C10X variant of CARD8 on the genetic risk of chronic inflammatory diseases particularly $\mathrm{CD}$. However, the results remain controversial [32-36].

Given the participation of CARD8 in the NLRP3 inflammasome complex, the role of NLRP3 inflammasome in the antibody response to yeast glycans, the structural similarities displayed by the proteins encoded by the CARD8, NOD2, NOD1 genes and their involvement in related pathways that modulate activation of immune cells and inflammation, the aim of this study was thus to investigate the relation between the p.C10X mutation of the CARD8 gene and antibody response to yeast glycans. As the p.C10X mutation was investigated in view of the antibody response to glycans in humans, we took advantage of the well-characterized antibody response to yeast glycans observed in families from Northern France with a strong aggregation of $\mathrm{CD}$ cases.

\section{Methods}

\section{Patients and study design}

$\mathrm{CD}$ families were recruited from the EPIMAD Registry [37]. Diagnosis of CD was based on the usual criteria, and phenotypes were defined according to the Montreal classification [38]. A peripheral venous blood sample was obtained from each participant at time of recruitment. The study protocol was approved by the ethics committee of the University Hospital of Lille, and informed written consent was obtained from all study participants.

ASCA, ALCA and ACCA levels and genotypes at rs2043211 were obtained for 200 subjects $(87$ men and 113 women) from $39 \mathrm{CD}$ pedigrees, among them 76 subjects were affected with $C D$. A subgroup of one CD proband per family and a subgroup of 39 HFDRs were constituted. When several HFDRs were eligible in a family, one HFDR was selected at random. A previous reported panel of control families was used to determine the allelic frequency of rs2043211 in a control population from the same geographic area [30].

\section{Genotyping}

Genotyping for rs2043211, which consists of a $\mathrm{T}$ to A transversion $(\mathrm{c} .30 \mathrm{~A}>\mathrm{T})$ located at the third nucleotide of codon 10 of $C A R D 8$, generating a premature stop codon (p.C10X) and a severely truncated CARD8 protein, was performed by PCR-RFLP. Briefly, DNA was extracted from whole blood using a QIAamp DNA blood kit (Qiagen, Valencia, CA, USA) and amplified with the forward primer 5'-GAGACAGAGGCAGAGC CATT-3' and reverse primer 5'-CCCCTGAGTTCGATG AAAAA-3'. The amplified fragment (175 bp) was then digested with DpnI (New England Biolabs, Ipswich, MA, USA), which recognizes the A allele, generating two fragments 150 and $25 \mathrm{bp}$ in size. The digestion products were run on a $4 \%$ agarose gel. Ten DNA samples were also sequenced with the same primers used for amplification, to verify the polymorphism. Genotypes at NOD2 (R702W, G908R, 1007fs insC) and at the NOD1 +32656 loci were determined using PCR-RFLP as previously described [30].

\section{Detection of anti-yeast glycan antibodies}

All sera were assayed using a panel of tests that detect ASCA, ALCA and ACCA (IBDX; Glycominds, Lod, 
Israel) [9]. This panel consists of kits involving three antigens: S. cerevisiae mannan, laminaribioside and chitobioside for the detection of ASCA, ALCA and ACCA, respectively. Para-nitrophenyl derivatives of each antigen were covalently bound to the surface of microtiter wells using a linking agent (oligomer of 1,8-diamino-3,6dioxaoctan; Sigma Chemical Co., St. Louis, MO, USA). These tests were performed according to the manufacturer's instructions. Antibody levels were expressed in arbitrary units (AU), relative to the manufacturer's calibrators. The antibody titers for each sample were calculated by dividing the average optical density (OD) of the sample by the average OD of the calibrator, multiplied by the number of units denoted by the calibrator tube label. Individuals were declared positive when levels of antibody in their sera were superior to 50, 60 and $90 \mathrm{AU}$ for ASCA, ALCA and ACCA, respectively.

\section{Statistical analyses}

Fitting the Hardy-Weinberg equilibrium, allelic frequencies and association with the disease were determined with the Haploview software [39]. The family-based association test implemented in the QTDT software [40] available at (http://www.sph.umich.edu/csg/abecasis/QTDT/index.html) was used to test for a genetic association between the p.C10X mutation and a quantitative trait in the 39 pedigrees. In QTDT analyses, empirical robust $p$ values were obtained following 10,000 Monte Carlo permutations. The CLUMP software [41] was used to compare allele frequencies. As a classical $\mathrm{Chi}^{2}$ test the CLUMP software allows comparison of frequencies between groups but a robust significance is assessed using repeated Monte Carlo permutations. Moreover, from the original $2 \times 4$ table (for the 4 groups of subjects) the CLUMP software clumps columns together in a new $2 \times 2$ table seeking to maximize $\mathrm{Chi}^{2}$ value allowing assessment of post-hoc tests whose robust significance is obtained using Monte Carlo permutations. All CLUMP analyses were performed following 100000 Monte Carlo permutations. When statistical investigations were not possible with the family-based association test implemented in the QTDT software, as there were families with more than one member affected with Crohn's disease, for a balanced influence of these families in "classical" statistical analyses, a subgroup of one CD proband per familiy was selected. Likewise for healthy relatives, a panel of one healthy relative selected at random in each family was established. Comparison of antibody responses was performed in the subgroups of $\mathrm{CD}$ probands and of HFDRs with the Wilcoxon Kruskal Wallis non-parametric test. The Chi2 test was used to compare the proportions of anti glycan positive subjects between CD patients and healthy relative subjects (HFDR). All "classical" statistical procedures were conducted with the JMP Pro 9.02 software (SAS Institute, Cary, NC).

\section{Results}

Distribution of the CARD8 p.C10X mutation (rs2043211) in the $\mathrm{CD}$ families and in control populations

Allelic frequencies were not significantly different between the $C D$ patients, the unaffected subjects $(p=0.89)$ of the $39 \mathrm{CD}$ families, the subjects from French control families and from the CEU panel of the HapMap version 3 release R2 (Table 1), but displayed a suggestive trend of association as analyzed by the CLUMP software $(\mathrm{p}=0.09)$. Post hoc tests disclosed that the chi2 was maximal when clumping subjects from French control families and HapMap subjects versus all subjects from our $\mathrm{CD}$ families: $\mathrm{CD}$ patients and unaffected subjects $(\mathrm{p}=0.06)$. There was a trend toward a lower frequency of the CARD8 p.C10X mutation in the population from the CD families as compared with reference (French control families and HapMap CEU) Caucasian populations (Table 1). However there was no association nor trend of association between the p.C10X CARD8 mutation and localization (L1, L2, L3, L4) and behavior (B1, B2, B3) of the disease according to the Montreal classification (data not shown).

As anti-glycan antibody levels are well known to be significantly higher in $\mathrm{CD}$ patients as compared to healthy subjects, all analyses were adjusted according to the affected/non-affected status.

\section{CARD8 p.C10X mutation is significantly negatively associated with ASCA levels in CD families}

In familial transmission tests (QTDT) adjusted by the CD status, including the whole population $(n=200)$ the p.C10X CARD8 mutation was significantly associated with a lower ASCA level $(\mathrm{p}=0.024)$. As we previously reported that ASCA levels were associated with the genotypes at the NOD2 (R702W, G908R, 1007fs insC) and at the NOD1 +32656 loci [30], QTDT analyses we adjusted according to the genotypes at the NOD2 and NOD1 loci. Thus ASCA levels remained significantly associated with the CARD8 p.C10X mutation ( $\mathrm{p}=0.023)$. Similar QTDT results were obtained in CD families for the association between the CARD8 p.C10X mutation and the binary trait ASCA positive or negative according to the 50 units threshold (Table 2).

In the subgroup of $39 \mathrm{CD}$ probands, ASCA levels were significantly lower according to the p.C10X genotype $(p=0.038$, Figure $1 \mathrm{~A})$ in agreement with the above reported familial QTDT analyses. In contrast, no significant association could be detected between the p.C10X CARD8 mutation and ASCA level in the subgroup of 39 HFDRs $(\mathrm{p}=0.64$, Figure $1 \mathrm{~B})$.

\section{CARD8 p.C10X mutation is significantly negatively associated with ALCA levels in CD families}

The results observed for anti-mannan antibodies (ASCA) levels prompted us to perform similar analyses on the 
Table 1 Allelic frequencies of the p.C10X mutation in the populations under study

\begin{tabular}{|c|c|c|c|c|c|c|}
\hline & & p.C10X MAF & $95 \% \mathrm{Cl}$ & $\begin{array}{c}\text { Comparison between the } \\
4 \text { groups (dof }=3 \text { ) }\end{array}$ & Comparison $(\mathrm{dof}=1)$ & Comparison $($ dof $=1)$ \\
\hline 1 & CD patients & 0.243 & {$[0.183-0.316]$} & $p=0.09$ & 1 vs. 2 & $1+2$ vs. $3+4$ \\
\hline 2 & $\begin{array}{l}\text { Healthy subjects from } \\
\text { CD families }\end{array}$ & 0.238 & {$[0.177-0.309]$} & & $p=0.89$ & $p=0.06$ \\
\hline 3 & French control families & 0.347 & {$[0.251-0.471]$} & & 3 vs. 4 & \\
\hline 4 & HapMap CEU & 0.315 & {$[0.271-0.361]$} & & $p=0.53$ & \\
\hline
\end{tabular}

Frequencies are those determined in pedigrees using the Haploview software. All frequencies comparisons were performed with the CLUMP software and robust p values were obtained following 100,000 Monte Carlo permutations. (MAF: minor allele frequency, dof: degree of freedom).

anti-glucan antibodies (ALCA), known to be associated with $\mathrm{CD}$ status and whose production was dependent on inflammasome activation. In familial transmission tests (QTDT) adjusted by the CD status, including the whole population $(\mathrm{n}=200)$, the p.C10X CARD8 mutation was significantly associated with a lower ALCA level $(\mathrm{p}=0.0035)$. Likewise this association remained largely significant following adjustment by the NOD2, NOD1 genotypes $(\mathrm{p}=0.0034)$. Similar QTDT results were obtained in CD families for the association between the CARD8 p.C10X mutation and the binary trait ALCA positive or negative according to the 60 units threshold (Table 2).

In the subgroup of $39 \mathrm{CD}$ probands there was a trend toward a lower ALCA level according to the p.C10X genotype $(\mathrm{p}=0.08$, Figure $2 \mathrm{~A})$. A similar analysis in the subgroup of 39 HFDR, did not detect a significant association $(\mathrm{p}=0.38$, Figure $2 \mathrm{~B})$.

ACCA levels are independent of CARD8 p.C10X mutation In familial transmission tests (QTDT) adjusted by the CD status including the whole population $(n=200)$, no association was observed between the p.C10X CARD8 mutation and the ACCA levels $(\mathrm{p}=0.577)$. Similarly, no associations were detected in the subgroups of $39 \mathrm{CD}$ probands and of $39 \operatorname{HFDR}$ ( $\mathrm{p}=0.95$ and $\mathrm{p}=0.22$, respectively).

\section{Distribution of anti-glycans antibody responders in the population examined}

Considering the subgroup of one CD proband per pedigree and the subgroup of HFDRs, anti-glycans antibody levels (ASCA, ALCA) were elevated in CD probands as compared with the group of healthy first-degree relatives
(HFDRs) in agreement with previously reported data [5,6]: ASCA levels were 78.7 \pm 77.6 for CD probands and $24.1 \pm 27.0$ for HFDRs $(\mathrm{p}<0.0001)$, ALCA levels $64.1 \pm 56.1$ for CD probands and 26.4 \pm 20.0 for HFDRs $(p=0.0002)$. The proportion of anti-glycans antibody positive subjects (Table 3) was in agreement with the data from the literature $[5,6]$.

In the $39 \mathrm{CD}$ probands subgroup there were less ASCA positive patients (45.0\%) in those having at least one p.C10X CARD8 mutation (dominant model) than in those being wild-type at this locus (63.2\%). Although this analysis on a limited number of subjects did not reach significance $(\mathrm{p}=0.2)$ it was in agreement with familial association results. Likewise in the subgroup of $39 \mathrm{CD}$ probands the ALCA positive CD patients were less frequent $(25.0 \%)$ in those with at least one p.C10X CARD8 mutation than in those who were wild-type $(52.6 \%)$ but this difference did not reach significance $(p=0.07)$. The proportion of CD patients being either ASCA or ALCA positive were $50.0 \%$ in those having at least one p.C10X CARD8 mutation versus $68.4 \%$ in the wild type ones $(\mathrm{p}=0.2)$.

\section{Discussion}

This study investigated the relationships between a mutation of the CARD8 gene encoding a component of inflammasome and antibody response in humans in the context of Crohn's disease (CD) where anti-yeast glycan antibodies are well documented. Our results show that decreased levels of antibody to mannan (ASCA) and Glucans (ALCA) but not chitin (ACCA) are associated with the CARD 8 p.C10X mutation. These results show

Table 2 Results of familial QTDT analyses including the whole population $(n=200)$

\begin{tabular}{|c|c|c|c|c|}
\hline & \multicolumn{2}{|c|}{ Adjusted by the CD status } & \multicolumn{2}{|c|}{ Adjusted by the CD status, and NOD2 and NOD1 genotypes } \\
\hline & $\mathrm{p}$ value & $Z$ for mutated allele & $p$ value & $\mathrm{Z}$ for mutated allele \\
\hline ASCA level & 0.024 & -24.59 & 0.023 & -24.58 \\
\hline ASCA binary trait (positive/negative) & 0.05 & -0.146 & 0.05 & -0.145 \\
\hline ALCA level & 0.0035 & -17.08 & 0.0034 & -17.17 \\
\hline ALCA binary trait (positive/negative) & 0.0025 & -0.232 & 0.0026 & -0.230 \\
\hline
\end{tabular}

The $Z$ values reflect the strength of associations; negatives values reflect an association with a lower level of the trait under study. Positive values would reflect association with a higher level of the trait. NOD2, (R702W, G908R, 1007fs insC mutations) and the NOD1 +32656 genotypes were from Vasseur et al. [30]. 

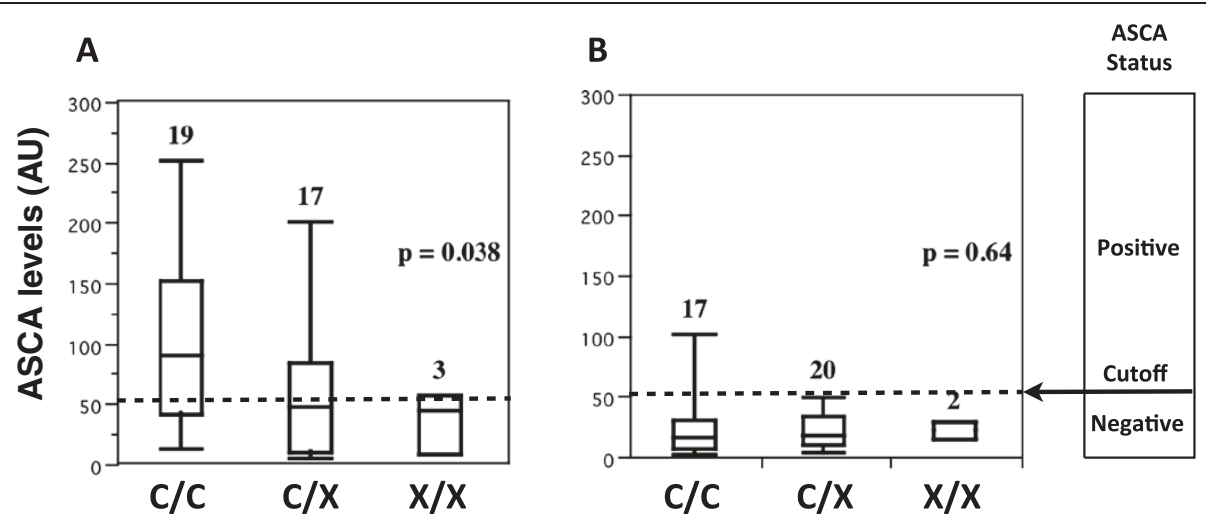

Figure 1 Measurement of anti-mannan antibody levels in human sera according to p.C10X genotype. Anti-mannan antibody (ASCA) levels were determined in sera from CD probands (A) and healthy first-degree relatives (B) by ELISA. Antibody titers (expressed in AU according to the reactivity of the manufacturer's calibrator) in samples from subjects who were wild-type $(C / C)$, heterozygous $(C / X)$, or homozygous $(X / X)$ for the p.C10X mutation. Positive or negative ASCA status was determined according to the cutoff value of 50 AU determined according to the manufacturer's instruction.

that the CARD8 p.C10X mutation, despite not being associated with Crohn's disease per se (at least in French Caucasians) is associated with some but not all antiyeast glycan antibody levels (ASCA and ALCA but not ACCA) in CD families.

Among several serological markers of $\mathrm{CD}$, the antiglycan response has been shown to be one of the main features of this disease $[4,42]$. The origin of this response is still unclear although the possible involvement of $C$. albicans has been proposed [8] and a link has been shown between Candida colonization and ASCA [43]. Although high ASCA levels are considered to be markers of $C D(60 \%$ of $C D$ patients are highly positive for ASCA), it is unclear why some CD patients do not have elevated ASCA levels independently of the gravity of the illness or of its location.
Compelling evidence have led to the consensus that $C D$ is a multifactorial disorder that results from an uncontrolled inflammatory response to endoluminal microorganisms in genetically predisposed individuals. To date, over 70 distinct genomic loci have been shown to confer susceptibility for CD [11]. Most of them encode or are located in the vicinity of genes that are involved in the inflammation process, the modulation of host-microbe interactions and in the maintenance of epithelial homeostasis in the gut. The most strongly association with $\mathrm{CD}$ has been shown for the gene coding the innate pattern recognition receptor NOD2/CARD15 [12]. However, other genes such as $C A R D 8$, located at an IBD locus, have also been shown to be involved in $\mathrm{CD}[35,36]$.

CARD8 is a protein whose function has not been fully elucidated. It is involved in regulation of pro inflammatory
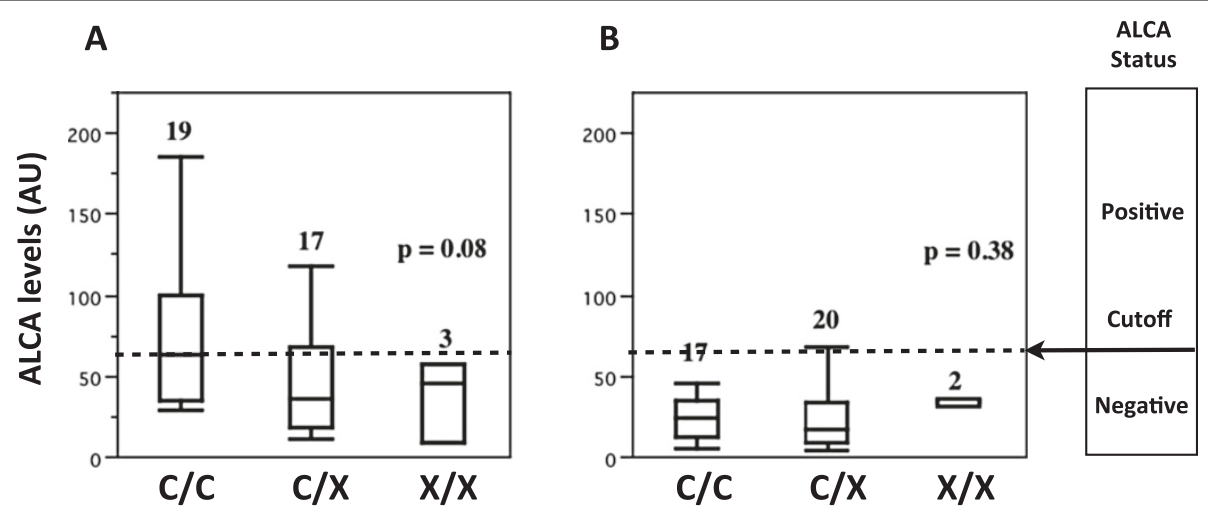

Figure 2 Measurement of anti-glucan antibody levels in human sera according to p.C10X genotype. Anti-glucan antibody (ALCA) levels were determined in sera from CD probands $(\mathbf{A})$ and healthy first-degree relatives $(\mathbf{B})$ by ELISA. Antibody titers (expressed in AU according to the reactivity of the manufacturer's calibrator) in samples from subjects who were wild-type (C/C), heterozygous (C/X), or homozygous (X/X) for the $p$. C10X mutation. Positive or negative ALCA status was determined according to the cutoff value of 60 AU determined according to the manufacturer's instruction. 
Table 3 Proportion of anti-glycans antibody positive subjects among the CD probands and the HFDRs

\begin{tabular}{|c|c|c|c|c|c|c|c|c|c|c|c|c|}
\hline & \multicolumn{4}{|c|}{ ASCA positive } & \multicolumn{4}{|c|}{ ALCA positive } & \multicolumn{4}{|c|}{ ASCA or ALCA positive } \\
\hline & $n$ & $\%$ & $95 \% \mathrm{Cl}$ & $p$ value & $\mathrm{n}$ & $\%$ & $95 \% \mathrm{Cl}$ & $p$ value & $n$ & $\%$ & $95 \% \mathrm{Cl}$ & $p$ value \\
\hline CD probands $(n=39)$ & 21 & 53.8 & {$[38.6-68.4]$} & $p<0.0001$ & 15 & 38.4 & {$[24.9-54.1]$} & $p=0.0008$ & 23 & 58.9 & {$[43.4-72.9]$} & $p<0.0001$ \\
\hline HFDR $(n=39)$ & 4 & 10.3 & {$[4.1-23.6]$} & & 3 & 7.7 & [2.7-20.3] & & 6 & 15.4 & [7.3-29.7] & \\
\hline
\end{tabular}

ASCA positivity was according to the $50 \mathrm{AU}$ threshold and ALCA positivity according to the $60 \mathrm{AU}$ threshold.

response involving NFkB [13] and was therefore proposed as a susceptibility gene for CD [34]. However, the association between CARD8 and $C D$ remains controversial $[44,45]$ although the influence of NFKB in ASCA production has been reported [46]. CARD8 also participates to the formation of inflammasome NLRP3 $[14,15]$ involved in innate immunity, thus impacting the cellular response based on caspase-1 and NFKB [47]. Using NLRP3 knockout mice, inflammasome has been shown to be important in production by phagocytic cells of IL-1 [19], a cytokine important in inflammatory processes and involved in the modulation of the adaptive immunity $[48,49]$. NLRP3 also plays a role in the adaptive immunity since it is implied in B-cell activation leading to production of anti-glycans antibody, in a manner independent of the innate immunity [19].

In agreement with the literature [44], our current results showed that the CARD8 mutation was not associated with $\mathrm{CD}$ in our panel of French families. On the other hand, the p.C10X allele was associated with a significantly lower antibody response with respect to glycans which are present on the surface of yeasts. Surprisingly, such association was not evidenced for antibody response directed against chitin, a wide spread component, highlighting a difference in either antigen presentation or regulation according to glycans. This is in accordance with the observation that B-cells from NLRP3 knockout mice are unable to produce antibodies after stimulation by glucans [19] suggesting that production of anti-glucan antibodies by B-cells is at least partly dependent on the activity of inflammasome. Although the putative biological link between the p.C10X mutation and the anti-glycans antibody response remains to be clarified these results represent the first clue as to a relationship between innate and adaptive immunity in $\mathrm{CD}$.

B-cells may be directly activated by glycans [50]. However, B-cell may also be activated by neutrophils through the production of the B-cell specific cytokine (BAFF) allowing natural immunoglobulins production by B-cells $[51,52]$. We previously reported that +32656 NOD1 insertion-deletion polymorphism associates with unresponsiveness towards glycans [30]. NOD1/CARD4 is an intracellular sensor for peptidoglycan from Gram-negative bacteria that plays an important role in neutrophil function, recruitment and activation [53]. Considering the role that NOD1 plays on neutrophils activation, which in turn may result on the alteration of B-cells activation and antibody production, we thus examined the possible relation between NOD1 polymorphism and CARD8 p.C10X mutation toward anti-glycans antibodies production. CARD8 $\mathrm{p}$. C10X mutation and +32656 NOD1 insertion-deletion polymorphism did not show any additive participation to anti-glycans modulation and CARD 8 mutation by itself associated with antibody production phenotype. Thus our observations suggest that CARD8 and NOD1 genetic variants independently associate with antibody levels through independent pathways without any detected additivity.

HFDRs analyzed separately did not show any significant association between ASCA, ALCA or ACCA and the CARD8 p.C10X mutation. However we cannot exclude that the low antibody levels observed in HFDRs make difficult the detection of a significant difference according to genotype, especially with a limited subgroup of subjects.

Severity of CD is associated with higher ASCA and ALCA levels $[54,55]$. This suggests a possible involvement of inflammasome in: (i) the production of proinflammatory cytokines such as IL-1 $\beta$ and secondarily IL-17 leading to the development of the CD inflammatory process [56,57]; and (ii) an effective anti-glycan response [19]. CARD8 has been shown to regulate NFkBdependent cell activities, it is thus anticipated that the absence of active CARD8, evidenced by an altered ASCA response, could be associated with a more favorable prognosis in terms of disease evolution. Here, we were unable to detect a significant association between the genetic alteration of CARD8 and the severity and location of the disease according to the Montreal classification [38].

\section{Conclusions}

The main result of our study is that decreased levels of anti-yeast glycan antibody levels are associated with the CARD8 p.C10X mutation in the families under investigation. Associations may be considered as confident as they were based on QTDT analyses including the whole population under study (200 subjects). Regarding the stratifyed analyses in the subgroup of 39 patients presenting Crohn's disease and of 39 healthy relatives, results may be interpreted with caution regarding the low number (39) of subjects included in the analyses. It is likely that $\mathrm{CD}$ affected patients have a major weight in 
the QTDT familial analyses and that the lack of anti glycan antibody difference association with CARD 8 p.C10X in the healthy relatives subgroup may reflect a lack of statistical power. Despite not being directly associated with Crohn's disease (at least in French Caucasians) the CARD8 p.C10X mutation, which is thought to affect regulation of inflammasome activity, is specifically associated with some anti-yeast glycan antibody levels (ASCA and ALCA) in CD families. Confirmation of a mechanistic role of CARD8 in anti-glycan antibody production may be important in better understanding the participation of inflammasome in adaptive response in particular against yeast components, but also for individual diagnosis in the case of patients presenting CARD8 mutation for whom ASCA levels would be low whatever the gravity of their disease.

\section{Competing interests}

The authors declare that they have no competing interests.

\section{Authors' contributions}

FV: carried out the studies and data analyses (statistics and genetics), and wrote the manuscript. BS: carried out the studies and data analyses (antibody response), participated to draft the manuscript. FB: participated to the genotyping. CGR: collected and organized the samples and helped to draft the manuscript. AS: carried out the genotyping. AVS: organized the samples and helped to draft the manuscript. DP: helped to draft the manuscript. JFC: helped to draft the manuscript. TJ: coordinated the study and wrote the manuscript. All authors read and approved the final manuscript.

\section{Acknowledgements}

The authors wish to thank the interviewing practitioners who collected data: V. Suffys, B. Lemaire, N. Guillon, I. Rousseau, A. Pétillon, P. Fosse, M. Leconte, C. Le Gallo, C. Dias, and S. Richon. The authors thank all gastroenterologists and other specialists who participated in this study.

A S was supported by a grant from Inserm/Région Nord Pas de Calais. T I was supported in part by AVIESAN.

This work was supported by Inserm and by the European Community's Seventh Framework Program (FP7-2007-2013) under grant agreement no. HEALTH-F2-2010-260338 'ALLFUN'.

EPIMAD is organized under an agreement between Inserm and the Institut National de Veille Sanitaire (InVS) and also received financial support from the François Aupetit Association, Lion's Club of Northern France, Ferring Laboratories, Astra-Zeneca Company (IRMAD), the Société Nationale Française de Gastroentérologie, Lille University Hospital.

\section{Author details}

${ }^{1}$ Université Lille Nord de France, 59000, Lille, France. ${ }^{2}$ UDSL, 59000, Lille, France. Inserm U995, Team 2, Faculté de Médecine H. Warembourg, Pôle Recherche, Place Verdun, F-59000, Lille, France. ${ }^{4}$ EA2694, 59000, Lille, France. ${ }^{5}$ Pôle de Santé Publique, 59000, Lille, France. ${ }^{6}$ Service des Maladies de I'Appareil Digestif et de la Nutrition, 59000, Lille, France. ${ }^{7}$ Service de Parasitologie Mycologie, Institut de Microbiologie, 59000, Lille, France. ${ }^{8}$ EA2679, 59000, Lille, France. ${ }^{9} \mathrm{CHRU}$ Lille, 59000, Lille, France.

Received: 19 June 2012 Accepted: 13 March 2013

Published: 18 March 2013

\section{References}

1. Alavi A, Axford JS: Sweet and sour: the impact of sugars on disease. Rheumatology (Oxford) 2008, 47(6):760-770.

2. Sendid B, Poirot JL, Tabouret M, Bonnin A, Caillot D, Camus D, Poulain D: Combined detection of mannanaemia and antimannan antibodies as a strategy for the diagnosis of systemic infection caused by pathogenic Candida species. J Med Microbiol 2002, 51(5):433-442.
3. Quinton JF, Sendid B, Reumaux D, Duthilleul P, Cortot A, Grandbastien B, Charrier G, Targan SR, Colombel JF, Poulain D: Anti-Saccharomyces cerevisiae mannan antibodies combined with antineutrophil cytoplasmic autoantibodies in inflammatory bowel disease: prevalence and diagnostic role. Gut 1998, 42(6):788-791.

4. Hedin CR, Stagg AJ, Whelan K, Lindsay JO: Family studies in Crohn's disease: new horizons in understanding disease pathogenesis, risk and prevention. Gut 2012, 61(2):311-318.

5. Poulain D, Sendid B, Fajardy I, Danze PM, Colombel JF: Mother to child transmission of anti-S cerevisiae mannan antibodies (ASCA) in non-IBD families. Gut 2000, 47(6):870-871.

6. Vermeire S, Joossens S, Peeters M, Monsuur F, Marien G, Bossuyt X, Groenen P, Vlietinck R, Rutgeerts P: Comparative study of ASCA (AntiSaccharomyces cerevisiae Antibody) assays in inflammatory bowel disease. Gastroenterology 2001, 120(4):827-833.

7. Sendid B, Quinton JF, Charrier G, Goulet O, Cortot A, Grandbastien B, Poulain D, Colombel JF: Anti-Saccharomyces cerevisiae mannan antibodies in familial Crohn's disease. Am J Gastroenterol 1998, 93(8):1306-1310.

8. Standaert-Vitse A, Jouault T, Vandewalle P, Mille C, Seddik M, Sendid B, Mallet J-M, Colombel J-F, Poulain D: Candida albicans is an immunogen for anti-Saccharomyces cerevisiae antibody markers of Crohn's disease. Gastroenterology 2006, 130(6):1764-1775.

9. Dotan I, Fishman S, Dgani Y, Schwartz M, Karban A, Lerner A, Weishauss O, Spector L, Shtevi A, Altstock RT, et al: Antibodies against laminaribioside and chitobioside are novel serologic markers in Crohn's disease. Gastroenterology 2006, 131(2):366-378.

10. Sendid B, Dotan N, Nseir S, Savaux C, Vandewalle P, Standaert A, Zerimech F, Guery BP, Dukler A, Colombel JF, et al: Antibodies against glucan, chitin, and Saccharomyces cerevisiae mannan as new biomarkers of Candida albicans infection that complement tests based on C. albicans mannan. Clin Vaccine Immunol 2008, 15(12):1868-1877.

11. Franke A, McGovern DPB, Barrett JC, Wang K, Radford-Smith GL, Ahmad T, Lees CW, Balschun T, Lee J, Roberts R, et al: Genome-wide meta-analysis increases to 71 the number of confirmed Crohn's disease susceptibility loci. Nat Genet 2010, 42(12):1118-1125.

12. Hugot JP, Chamaillard M, Zouali H, Lesage S, Cézard JP, Belaiche J, Almer S, Tysk C, O'Morain CA, Gassull M, et al: Association of NOD2 leucine-rich repeat variants with susceptibility to Crohn's disease. Nature 2001, 411(6837):599-603.

13. Bouchier-Hayes L, Conroy H, Egan H, Adrain C, Creagh EM, MacFarlane M, Martin SJ: CARDINAL, a novel caspase recruitment domain protein, is an inhibitor of multiple NF-kappa B activation pathways. J Biol Chem 2001, 276(47):44069-44077.

14. Agostini L, Martinon F, Burns K, McDermott MF, Hawkins PN, Tschopp J: NALP3 forms an IL-1 beta-processing inflammasome with increased activity in Muckle-Wells autoinflammatory disorder. Immunity 2004, 20(3):319-325.

15. Martinon F, Tschopp J: Inflammatory caspases: linking an intracellular innate immune system to autoinflammatory diseases. Cell 2004, 117(5):561-574.

16. Hornung V, Bauernfeind F, Halle A, Samstad EO, Kono H, Rock KL, Fitzgerald KA, Latz E: Silica crystals and aluminum salts activate the NALP3 inflammasome through phagosomal destabilization. Nat Immunol 2008, 9(8):847-856.

17. Hise AG, Tomalka J, Ganesan S, Patel K, Hall BA, Brown GD, Fitzgerald KA: An essential role for the NLRP3 inflammasome in host defense against the human fungal pathogen Candida albicans. Cell Host Microbe 2009, 5(5):487-497.

18. Joly S, Ma N, Sadler JJ, Soll DR, Cassel SL, Sutterwala FS: Cutting edge: Candida albicans hyphae formation triggers activation of the Nlrp3 inflammasome. J Immunol 2009, 183(6):3578-3581.

19. Kumar H, Kumagai Y, Tsuchida T, Koenig PA, Satoh T, Guo Z, Jang MH, Saitoh T, Akira S, Kawai T: Involvement of the NLRP3 inflammasome in innate and humoral adaptive immune responses to fungal beta-glucan. J Immunol 2009, 183(12):8061-8067.

20. Saïd-Sadier N, Padilla E, Langsley G, Ojcius DM: Aspergillus fumigatus stimulates the NLRP3 inflammasome through a pathway requiring ROS production and the Syk tyrosine kinase. PLoS One 2010, 5(4):e10008.

21. Bellocchio S, Montagnoli C, Bozza S, Gaziano R, Rossi G, Mambula SS, Vecchi A, Mantovani A, Levitz SM, Romani L: The contribution of the Toll-like/IL-1 receptor superfamily to innate and adaptive immunity to fungal pathogens in vivo. J Immunol 2004, 172(5):3059-3069. 
22. Mencacci A, Bacci A, Cenci E, Montagnoli C, Fiorucci S, Casagrande A, Flavell RA, Bistoni F, Romani L: Interleukin 18 restores defective Th1 immunity to Candida albicans in caspase 1-deficient mice. Infect Immun 2000, 68(9):5126-5131.

23. Netea MG, Simon A, van de Veerdonk F, Kullberg B-J, van der Meer JWM, Joosten LAB: IL-1beta Processing in Host Defense: Beyond the Inflammasomes. PLoS Pathog 2010, 6(2):e1000661.

24. Stuyt RJL, Netea MG, Verschueren I, Fantuzzi G, Dinarello CA, van der Meer JWM, Kullberg BJ: Role of interleukin-18 in host defense against disseminated Candida albicans infection. Infect Immun 2002, 70(6):3284-3286

25. Vonk AG, Netea MG, van Krieken JH, Iwakura Y, van der Meer JWM, Kullberg BJ: Endogenous interleukin (IL)-1 alpha and IL-1 beta are crucial for host defense against disseminated candidiasis. J Infect Dis 2006, 193(10):1419-1426.

26. Eisenbarth SC, Colegio OR, O'Connor W, Sutterwala FS, Flavell RA: Crucial role for the Nalp3 inflammasome in the immunostimulatory properties of aluminium adjuvants. Nature 2008, 453(7198):1122-1126.

27. Kool M, Pétrilli V, De Smedt T, Rolaz A, Hammad H, van Nimwegen M, Bergen IM, Castillo R, Lambrecht BN, Tschopp J: Cutting edge: alum adjuvant stimulates inflammatory dendritic cells through activation of the NALP3 inflammasome. J Immuno/ 2008, 181(6):3755-3759.

28. Kankkunen $P$, Teirilä L, Rintahaka J, Alenius H, Wolff H, Matikainen S: (1,3)\{beta\}-Glucans Activate Both Dectin-1 and NLRP3 Inflammasome in Human Macrophages. J Immunol 2010, 184(11):6335-6342.

29. Petterson T, Jendholm J, Månsson A, Bjartell A, Riesbeck K, Cardell L-O: Effects of NOD-like receptors in human $B$ lymphocytes and crosstalk between NOD1/NOD2 and Toll-like receptors. J Leukoc Biol 2010, 89(2):177-187.

30. Vasseur F, Sendid B, Jouault T, Standaert-Vitse A, Dubuquoy L, Francois N, Gower-Rousseau C, Desreumaux P, Broly F, Vermeire S, et al: Variants of NOD1 and NOD2 genes display opposite associations with familial risk of Crohn's disease and anti-saccharomyces cerevisiae antibody levels. Inflamm Bowel Dis 2012, 18(3):430-438.

31. Dassopoulos T, Frangakis C, Cruz-Correa M, Talor MV, Burek CL, Datta L, Nouvet F, Bayless TM, Brant SR: Antibodies to saccharomyces cerevisiae in Crohn's disease: higher titers are associated with a greater frequency of mutant NOD2/CARD15 alleles and with a higher probability of complicated disease. Inflamm Bowel Dis 2007, 13(2):143-151.

32. Henckaerts $L$, Pierik $M$, Joossens $M$, Ferrante $M$, Rutgeerts $P$, Vermeire $S$ : Mutations in pattern recognition receptor genes modulate seroreactivity to microbial antigens in patients with inflammatory bowel disease. Gut 2007, 56(11):1536-1542.

33. Kastbom A, Johansson M, Verma D, Soderkvist $P$, Rantapaa-Dahlqvist S: CARD8 p.C10X polymorphism is associated with inflammatory activity in early rheumatoid arthritis. Ann Rheum Dis 2010, 69(4):723-726.

34. McGovern DPB, Butler $H$, Ahmad T, Paolucci M, van Heel DA, Negoro K, Hysi $P$, Ragoussis J, Travis SPL, Cardon LR, et al: TUCAN (CARD8) genetic variants and inflammatory bowel disease. Gastroenterology 2006 131(4):1190-1196.

35. Roberts RL, Topless RK, Phipps-Green AJ, Gearry RB, Barclay ML, Merriman TR: Evidence of interaction of CARD8 rs2043211 with NALP3 rs35829419 in Crohn's disease. Genes Immun 2010, 11(4):351-356.

36. Schoultz I, Verma D, Halfvarsson J, Törkvist L, Fredrikson M, Sjöqvist U, Lördal M, Tysk C, Lerm M, Söderkvist P, et al: Combined polymorphisms in genes encoding the inflammasome components NALP3 and CARD8 confer susceptibility to Crohn's disease in Swedish men. Am J Gastroenterol 2009, 104(5):1180-1188.

37. Molinié F, Gower-Rousseau C, Yzet T, Merle V, Grandbastien B, Marti R, Lerebours E, Dupas J-L, Colombel J-F, Salomez J-L, et al: Opposite evolution in incidence of Crohn's disease and ulcerative colitis in Northern France (1988-1999). Gut 2004, 53(6):843-848.

38. Satsangi J, Silverberg MS, Vermeire S, Colombel J-F: The Montreal classification of inflammatory bowel disease: controversies, consensus, and implications. Gut 2006, 55(6):749-753.

39. Barrett JC, Fry B, Maller J, Daly MJ: Haploview: analysis and visualization of LD and haplotype maps. Bioinformatics 2005, 21(2):263-265.

40. Abecasis GR, Cardon LR, Cookson WO: A general test of association for quantitative traits in nuclear families. Am J Hum Genet 2000, 66(1):279-292
41. Sham PC, Curtis D: Monte Carlo tests for associations between disease and alleles at highly polymorphic loci. Ann Hum Genet 1995, 59(Pt 1):97-105.

42. Li $\mathrm{X}$, Conklin L, Alex P: New serological biomarkers of inflammatory bowel disease. World J Gastroenterol 2008, 14(33):5115-5124.

43. Standaert-Vitse A, Sendid B, Joossens M, François N, Vandewalle-El Khoury P, Branche J, Van Kruiningen $H$, Jouault T, Rutgeerts P, Gower-Rousseau C, et al: Candida albicans Colonization and ASCA in Familial Crohn's Disease. Am J Gastroenterol 2009, 104(7):1745-1753.

44. Fisher SA, Mirza MM, Onnie CM, Soars D, Lewis CM, Prescott NJ, Mathew CG, Sanderson J, Forbes A, Todhunter C, et al: Combined evidence from three large British Association studies rejects TUCAN/CARD8 as an IBD susceptibility gene. Gastroenterology 2007, 132(5):2078-2080.

45. Yang S-K, Kim H, Hong M, Lim J, Choi E, Ye BD, Park S-K, Song K: Association of CARD8 with inflammatory bowel disease in Koreans. J Hum Genet 2011, 56(3):217-223.

46. Takedatsu H, Taylor KD, Mei L, Mcgovern DPB, Landers CJ, Gonsky R, Cong Y, Vasiliauskas EA, Ippoliti A, Elson CO, et al: Linkage of Crohn's diseaserelated serological phenotypes: NFKB1 haplotypes are associated with anti-CBir1 and ASCA, and show reduced NF-kappaB activation. Gut 2009, 58(1):60-67.

47. von Kampen O, Lipinski S, Till A, Martin SJ, Nietfeld W, Lehrach H, Schreiber $\mathrm{S}$, Rosenstiel P: Caspase recruitment domain-containing protein 8 (CARD8) negatively regulates NOD2-mediated signaling. J Biol Chem 2010, 285(26):19921-19926.

48. Dinarello CA: IL-1: Discoveries, controversies and future directions. Eur J Immunol 2010, 40(3):599-606.

49. Nambu A, Nakae S, Iwakura Y: IL-1beta, but not IL-1alpha, is required for antigen-specific T cell activation and the induction of local inflammation in the delayed-type hypersensitivity responses. Int Immunol 2006, 18(5):701-712.

50. Harnack U, Kellermann U, Pecher G: Yeast-derived Beta-(1-3), (1-6)-Dglucan Induces Up-regulation of CD86 on Dectin-1-positive Human BLymphoma Cell Lines. Anticancer Res 2011, 31(12):4195-4199.

51. Puga I, Cols M, Barra CM, He B, Cassis L, Gentile M, Comerma L, Chorny A, Shan $M, X u$ W, et al: B cell-helper neutrophils stimulate the diversification and production of immunoglobulin in the marginal zone of the spleen. Nat Immunol 2011, 13(2):170-180.

52. Bordon Y: Antibody responses: Neutrophils zone in to help B cells. Nat Rev Immunol 2012, 12(2):73

53. Dharancy S, Body-Malapel M, Louvet A, Berrebi D, Gantier E, Gosset P, Viala J, Hollebecque A, Moreno C, Philpott DJ, et al: Neutrophil migration during liver injury is under nucleotide-binding oligomerization domain 1 control. Gastroenterology 2010, 138(4):1546-1556. 1556 e1541-1545.

54. Russell RK, Ip B, Aldhous MC, MacDougall M, Drummond HE, Arnott IDR, Gillett PM, McGrogan P, Weaver LT, Bisset WM, et al: Anti-Saccharomyces cerevisiae antibodies status is associated with oral involvement and disease severity in Crohn disease. J Pediatr Gastroenterol Nutr 2009, 48(2):161-167

55. Walker L, Aldhous MC, Drummond HE, Smith BRK, Nimmo ER, Arnott IDR, Satsangi J: Anti-Saccharomyces cerevisiae antibodies (ASCA) in Crohn's disease are associated with disease severity but not NOD2/CARD15 mutations. Clin Exp Immunol 2004, 135(3):490-496.

56. Dinarello CA: Immunological and inflammatory functions of the interleukin-1 family. Annu Rev Immunol 2009, 27:519-550.

57. Rehaume LM, Jouault T, Chamaillard M: Lessons from the inflammasome: a molecular sentry linking Candida and Crohn's disease. Trends Immunol 2010, 31(5):171-175.

doi:10.1186/1471-2350-14-35

Cite this article as: Vasseur et al:: The CARD8 p.C10X mutation associates with a low anti-glycans antibody response in patients with Crohn's disease. BMC Medical Genetics 2013 14:35 